\title{
A review of previous studies on ESL/EFL learners' interactional feedback exchanges in face-to-face and computer-assisted peer review of writing
}

Open Access

\author{
Murad Abdu Saeed ${ }^{1 *}$, Kamila Ghazali ${ }^{1}$ and Musheer Abdulwahid Aljaberi ${ }^{2}$
}

\footnotetext{
* Correspondence:

murad.mohammed13@yahoo.com

${ }^{1}$ Faculty of Languages and Linguistics, University of Malaya,

Kuala Lumpur, Malaysia

Full list of author information is

available at the end of the article
}

\begin{abstract}
This paper is a review of previous studies on learners' interactional feedback exchanges in face-to-face peer review (FFPR) and computer-assisted peer review (CAPR) of English as Second/Foreign Language (ESL/EFL) writing. The review attempted to (1) identify the patterns of interactional feedback, (2) search an empirical evidence of learners' incorporation of peer interactional feedback in their text revisions and (3) identify the factors affecting learners' interactional feedback as reported in these previous studies. To achieve this, a search of previous studies on peer review in writing from 1990 to 2016 was conducted. However, only 37 out of 58 peer reviewed studies were extensively reviewed and systematically analyzed by two independent coders. The findings showed that in terms of the language functions, learners' interactional feedback exchanges are categorized as (1) exploratory (showing learners' reflection and interpretation of the task), (2) procedural (showing how learners handle the task of revising their texts) and (3) social (showing how learners maintain good relationships). In relation to the nature and focus areas, learners' interactional feedback exchanges are revision-oriented (targeting problems or errors in written texts) and non-revision-oriented (do not target any problems). Results of some previous reviewed studies also provided evidence of learners' integration of peer feedback into their text revisions. However, peer interactional feedback is affected by several factors: training learners on feedback, mode of peer review, type of written tasks, learners' roles in peer review activties, learners' proficiency in English and other factors, including learners' gender differences and configuration of peer review dyads as well as context of peer review. Synthesizing the findings of the reviewed studies, we proposed a dual space-interactional feedback model that comprises the learning space and the social space of interactional feedback in peer review. Several pedagogical, research and technological implications were also drawn from the major findings. Future researchers should pay attention to both spaces of interactional feedback and identify further factors affecting interactional feedback in peer review.
\end{abstract}

Keywords: Feedback exchanges, Text revision, Face-to-face-peer review, Computerassisted peer review 


\section{Introduction}

Peer/group review in writing, also known as peer response, peer revision (McGroarty \& Zhu, 1997), peer feedback (Zhu, 2001; Hyland \& Hyland, 2006) or peer evaluation (Stanley, 1992), has attracted the attention of many second language (L2) and foreign language (FL) writing practitioners and researchers (Hedge, 2001; Hyland \& Hyland, 2006; Hu \& Lam, 2010). This is because peer review fits well within the process approach to writing instruction in English as Second/Foreign Language (ESL/EFL) contexts. Its pedagogical value is attributed to its role in motivating learners to become sources of corrective feedback rather than the instructor $(\mathrm{Hu}, 2005$; Hyland \& Hyland, 2006). Peer review also helps learners to evaluate their texts, detect various problems and solve them through text modifications (Min, 2005, 2006; Hanjani \& Li, 2014).

From the socio-cultural approach (Vygotsky, 1987), particularly the notions of scaffolding and regulation, as stated by some researchers (eg., Levi Altstaedter, 2016; Yang, 2011), peer review is a constructive or collaborative activity in which students negotiate the intended ideas and meaning and mutually scaffold each other. Within this theory, peer review provides learners with opportunities to exchange multiple corrective feedback and articulate their knowledge of L2 (Hyland \& Hyland, 2006). Research grounded on Vygotsky's (1978) sociocultural theory and the interactionist theory (Swain \& Lapkin, 1998, 2002) indicates that peer review engages learners in scaffolding or assisting each other within the Zone of Proximal Development (ZPD) to solve problems in writing and in using the language for negotiations, thus modifying their output (Villamil \& De Guerrero, 1996; De Guerrero \& Villamil, 2000; Hyland \& Hyland, 2006; Hanjani \& Li, 2014).

Recently, studies into the applications of asynchronous and synchronous technologies to ESL/EFL group writing in general and peer review in particular (Darhower, 2002; Jones, Garralda, Li, \& Lock, 2006; Liang, 2010; Razak \& Saeed, 2014) have focused on learners' interactional/feedback exchanges based on the belief that understanding learners' interaction is a way to understand their cognitive engagement processes such as thinking.

Therefore, the review reported in this paper aimed to provide a synthesis of 37 previous empirical studies on ESL/EFL learners' interactional feedback exchanges in peer review in writing published from 1990 to 2016. However, since the interests of individual researchers vary, and reporting each study in detail is not necessary, the focus of the review is on the patterns of peer interactional feedback, the role of interactional feedback in improving learners' text revisions and major factors affecting learners' interactional feedback in peer review. It attempted to answer the following specific research questions:

(1) What are the patterns of ESL/EFL learners' interactional feedback exchanges in peer review in writing as identified in previous studies from 1990 to 2016?

(2) Is there empirical evidence of learners' incorporation of peer interactional feedback exchanges in their text revisions?

(3) What are the major factors that affect ESL/EFL learners' interactional feedback exchanges in peer review?

In the next sections, we discuss the main theories used as the basis for investigating learners' feedback in peer review and explain our methodology. Then, we provide a detailed discussion of the synthesized findings of the reviewed studies according to the three research questions. The paper is concluded by useful 
implications for ESL/EFL pedagogy of writing and technology use in peer review and recommendations for future research.

\section{Literature review}

Investigation of peer review in ESL/EFL writing reported in previous research is grounded on several theories in different disciplines, most important of which are the process writing theory (Hayes \& Flower, 1980), the sociocultural theory (Vygotsky, 1978) and the interactionist theory (Swain \& Lapkin, 1998, 2002). First, the process writing theory, which marks a remarkable shift in the views and practices of ESL writing from a finished text/product to a dynamic process, is one of the theoretical bases that inform the application of peer review to writing courses (Hayes \& Flower, 1980). Within this theoretical perspective, peer review plays an important role in assisting learners to produce multiple text revisions of their writing. Proponents of the process writing approach also argue that peer review is not only the last stage of the process writing approach that follows prewriting and writing stages, but it is also a dynamic and recursive process in which learners discover and negotiate intended meanings and ideas in their writing through feedback and revise their texts accordingly (Saeed \& Ghazali, 2016).

Within the sociocultural theory (Vygotsky, 1978), the concept of ZPD has been associated with another notion that is central to this theory, scaffolding. It is a term that refers to the various forms of supportive behaviours by which one learner can assist another peer to achieve higher levels of regulation (De Guerrero \& Villamil, 2000). Researchers investigating peer review from this theoretical perspective have reported that peer review engages learners in exchanging reciprocal scaffolding that assists them in targeting issues in their writing and solving them through revisions (e.g., Villamil \& De Guerrero, 1996; De Guerrero \& Villamil, 2000; Hanjani \& Li, 2014).

From the interactionist theory (Long, 1983, 1985; Swain \& Lapkin, 1998, 2002; Swain, 2006), the application of peer review to writing is based on the assumption that peer review activities encourage learners to exchange peer feedback. Such feedback exchanges facilitate learners' language development in general and in particular, writing skill. This is because peer feedback provides learners with sufficient input and opportunities to use the language for negotiation and thus, modify their output and enhance their writing (Hyland \& Hyland, 2006).

ESL/EFL writing instructors and researchers have paid considerable attention to the application of peer review in writing courses. They showed a great interest in applying peer review either in the form of face-to-face peer review (FFPR) (e.g., Mendonca \& Johnson, 1994; Lockhart \& Ng, 1995; Zhu, 1995; Villamil \& De Guerrero, 1996; De Guerrero \& Villamil, 2000; Hanjani \& Li, 2014) or in compter-assisted peer review (CAPR) by integrating various technological tools, including synchronous and asynchronous tools (e.g., Liou \& Peng, 2009; Chang, 2012; Bradley, 2014; Ho, 2015). One of the most interesting aspects of peer review for investigation has been ESL/EFL learners' feedback/interactional exchanges. In other words, as learners engage in peer review, they interact either orally as in the case of FFPR or synchronously/asynchronously as in the case of CAPR. Such peer feedback/interactional exchanges are recognized by many of the above cited researchers as a means to negotiating meanings or ideas in writing, increasing reader awareness, exchanging scaffolds or support, developing learners' communication skills, promoting their self-regulation and developing their learning autonomy. 
Previous researchers have also looked at ESL/EFL learners' feedback/interactional exchanges. Results indicate that peer review engages learners in exchanging feedback that functions as evaluations, suggestions, clarifications and questions (Mendonca \& Johnson, 1994; Lockhart \& Ng, 1995; Zhu, 1995; Villamil \& De Guerrero, 1996; De Guerrero \& Villamil, 2000; Hanjani \& Li, 2014). Similar patterns of peer feedback/interactional exchanges have been identified in electronic peer review activities, in addition to other patterns, including alterations (Bradley, 2014; Chang, 2012; Ho, 2015; Liou \& Peng, 2009; Liu \& Sadler, 2003) as well as agreements and disagreements (Di Giovanni \& Nagaswami, 2001) and advice exchanges (Tuzi, 2004). Most of these studies also highlight the role of peer feedback exchanges in peer review in identifying issues at the global and local levels of written texts.

\section{Methodology}

This section provides a systematic description of the methodology used in our review of previous related studies on ESL/EFL learners' peer review of writing. Specfically, it describes the sources and phases of searching previous studies as well as determination for inclusion and exclusion and coding and interpreting the results as follows:

\section{Data collection}

The current review followed five phases: (1) identification of keywords/themes, (2) searching relevant sources, (3) determination for inclusion, (4) coding and (5) analyzing and interpreting. The first phase was concerned with identifying these keywords: feedback, interaction, commenting patterns, peer feedback, peer review, peer revision, peer correction, peer response, peer evaluation, language functions, focus areas of comments, scope of peer feedback, FFPR, CAPR, synchronous and asynchronous peer review and ESL/EFL writing.

The second phase was exhaustive searching relevant sources. These sources include searching online databases such as ERIC, Educational Abstracts, PsychLit, and Dissertation Abstracts, Searching Google Scholar, searching websites known to reference or contain research related to educational technology such as research gate and linkedin, searching many scholarly e-journals and using general search engines (e.g., Google) in keyword searches for further manuscripts that either had not yet been catalogued in ERIC or were currently under refereed journal review (yet posted on the researcher's own webpage).

For the international refereed journals, we targeted these journals: Journal of Second Language Writing, Computers and Composition, Computer Assisted Language Learning, Language Learning \& Technology, Computers \& Education, Australasian Journal of Educational Technology, British Journal of Educational Technology, Journal of English for Academic Purposes, Language learning, Journal of Business and Technical Communication, Journal of Computer Assisted Learning, Learning and Instruction,Computers in Human Behavior, Research in the Teaching of English, Language Teaching Research, Instructional Science, Innovation in Language Learning and Teaching, TESOL Quarterly, Electronic Journal of Foreign Language Teaching, Suranaree Journal of Science and Technology, Multimedia Assisted Language Learning, CALICO Journal, The Modern Language Journal, ELT 
Journal, System, AsiaCall Online Journal, Journal of Science Ho Chi Minh City Open University, Written Communication, Educational Technology Research and Development, English Language Teaching and Language Teaching.

The third phase was determination for inclusion. This included only studies meeting the following criteria:

(1) Being published in the period from 1990 to 2016.

(2) Had to be carried out in ESL/EFL writing courses.

(3) Had to be focusing on FFPR and or CAPR, specifically interactional feedback.

(4) Had to use a clear analysis of feedback, including qualitative, quantitative or a mixture of both analyses. In other words, the analysis of feedback exchanges should include a clear description of the definitions of the various patterns of feedback exchanges found or identfied in learners' peer review of writing in these reviewed studies as well as illustrations of patterns with clear examples extracted from learners' interaction.

(5) Had to have clearly described research contexts, including participants, welldescribed data collection procedure, particularly the activities in peer review, interpretation and discussion of the findings and implications as well as limitations.

We selected the period from 1990 to 2016 for several reasons. First, we wanted to see the development of research on peer feedback in ESL/EFL writing over one and half decades. Secondly, we noticed that studies looking into peer feedback interactional exchanges that are published online and accessible are dated back to the early 1990 (e.g. Stanley, 1992; Beason, 1993). Thirdly, 2016 marks the year during which we finished analyzing the data and writing the first version of the review paper.

The research papers $(N=52)$ were evaluated based on the above cited inclusion criteria by the researcher and another coder who is also a researcher. Based on this, only 37 individual studies could meet the above criteria, and therefore, they were used for the analysis in the current review. As shown in the Additional file 1, the reviewed studies were conducted during (1990-2016). They were also carried out on peer review in writing among learners from different countries that are identified as ESL and EFL contexts. This is discussed in details in the finding section of this review as one factor, labeled context of peer review.

Moreover, the mode of peer review in each study was identified: a FFPR only, a CAPR only, or a combination of both FFPR and CAPR. Once again, for these studies focusing on CAPR, we identified the mode of peer feedback exchanges based on the technological tools used: synchronous, asynchronous, or a combination of synchronous and asynchronous CAPR. Out of the 37 reviewed studies, 15 previous studies focused on FFPR only (Stanley, 1992; Beason, 1993; Mendonca \& Johnson, 1994; Lockhart \& Ng, 1995; Zhu, 1995; Mendonca \& Johnson, 1994; Villamil \& De Guerrero, 1996; McGroarty \& Zhu, 1997; De Guerrero \& Villamil, 2000; Zhu, 2001; Min, 2005; Cho \& Cho, 2011; Lina \& Samuel, 2013; Vorobel \& Kim, 2014; Hanjani \& $\mathrm{Li}, 2014)$. On the other hand, an equal number of studies $(N=15)$ concentrated on CAPR only (Tuzi, 2004; Hewett, 2006; Guardado \& Shi, 2007; Liang, 2008, 2010; Liou \& Peng, 2009; Ho \& Usaha, 2009; Anderson, Bergman, Bradley, Gustafsson, \& Matzke, 2010; Cha \& Park, 2010; Ho, 2010; Ho \& Usaha, 2013; Bradley, 2014; Razak \& Saeed, 2014; Pham \& Usaha, 2015; Saeed \& Ghazali, 2016). Other remaining studies $(N=7)$ combined both FFPR and CAPR (Sullivan \& Pratt, 1996; Di Giovanni \& 
Nagaswami, 2001; Liu \& Sadler, 2003; Jones et al., 2006; Song \& Usaha, 2009; Chang, 2012; Ho, 2015).

So for the last two groups of studies $(N=22)$ that employed CAPR only and those that combined FFPR and CAPR, we also identified whether CAPR in these studies was synchronous or asynchronous, or a combination of synchronous or asynchronous. In this regard, of these 22 studies, most of them $(N=12)$ used asynchronous CAPR only (Sullivan \& Pratt, 1996; Tuzi, 2004; Liou \& Peng, 2009; Ho \& Usaha, 2009; Song \& Usaha, 2009; Ho, 2010; Ho \& Usaha, 2013; Bradley, 2014; Razak \& Saeed, 2014; Ho, 2015; Pham \& Usaha, 2015; Saeed \& Ghazali, 2016). However, 6 studies employed synchronous CAPR only (Hewett, 2006; Jones et al., 2006; Anderson et al., 2010; Liang, 2008, 2010; Cha \& Park, 2010), and other studies $(N=4)$ used a combination of both synchronous and asynchronous CAPR (Di Giovanni \& Nagaswami, 2001; Liu \& Sadler, 2003; Guardado \& Shi, 2007; Chang, 2012).

The research method, particulary analysis followed by each study was also identified, with an emphasis on the type of analysis: qualitative, mixed or quantitative. Finally, the findings and discussions of each study were thoroughly reviewed, coded, analyzed and interpreted as follows:

\section{Coding, analyzing and interpretation}

Prior to coding the findings of the selected papers for our review, another researcher was invited as a second coder. He was informed of the purpose and research questions of this review. Then, they discussed why these 37 studies were selected for review. After this, they started coding. Coding was performed based on the grounded theory by Glaser and Strauss (1967).

Each coder had to read the findings of each study. Coding the findings of these previous studies involved both substantive coding and theoretical coding. While substantive coding focuses on conceptualizing the empirical findings of these previous studies into substantive codes, theoretical coding focuses on relating or integrating such findings or codes into a research model (Glaser, 1978). For the substantive coding in this study, the coders independently coded each previous study. Based on the first round of reading of the selected studies, the two coders met face-to-face and discussed the initial emerging findings. This open coding allowed them to understand the various aspects of investigation of peer review in these selected studies, including feedback, text revisions, perception and even factors. This was followed by several rounds of readings and selective coding. Selective coding focused on patterns of peer feedback reported in these studies, incorporation of feedback into text revisions and factors affecting peer feedback. The coders had several study-by-study basis discussions. Moreover, they contacted each other via whats up group where they engaged in discussing several aspects of coding previous studies, including the patterns, themes and categories generated. They iteratively coded the findings/results of previous studies $(N=37)$. For those coding discrepancies, they were discussed and resolved by consulting the original research study.

For the patterns of interactional feedback exchanges, the iterative coding process resulted into many codes that were categorized into two main categories: the language functions of interactional feedback and nature and focus areas of interactional feedback. 
The language functions of interactional feedback were also clustered into three subcategories: exploratory, procedural and social. Regarding the second main category, the nature and focus areas of interactional feedback, it has two sub-categories: revisionoriented and non-revision-oriented. The revision-oriented sub-category comprises: global and local which are all discussed in "Findings and discussion" section. Clustering the different patterns of feedback exchanges in terms of the language functions and the nature and focus areas of such feedback patterns allowed us to make a synthesis of the various patterns of learners' feedback in the form of main categories. Another reason for such clustering of the patterns of feedback into main categories is to obtain an understanding of whether the learners as reported in previous studies engage highly in the task of peer review, the procedure itself or social aspects and whether their feedback exchanges targets global issues or local issues of written texts in peer review of writing.

Finally, the findings of previous studies reviewed in this paper were coded in terms of the integration of peer feedback into learners' text revisions and the factors affecting such interactional feedback. Besides the various factors affecting peer review that were identified and reported by some previous researchers as part of their research objectives and analysis, we looked at the context of peer review in each study, including the ESL/EFL contexts, the socio-cultural backgrounds of learners participating in peer review and the institutions and programs in which writing and peer review took place. This was pursued or continued till almost an agreement of $96 \%$ between the two coders was achieved.

\section{Findings and discussion}

This section presents the findings of the current study in an attempt to answer the three research questions stated in the introduction:

\section{What are the patterns of ESL/EFL learners' interactional feedback exchanges in peer review in writing as identified in previous studies from 1990 to 2016?}

This sub-section discusses the types of interactional feedback exchanges as identified in previous studies and as categorized in this paper in terms of the language functions and then, the focus areas of commenting patterns in both modes of peer review: FFPR and CAPR.

\section{The language functions of interactional feedback exchanges in peer review}

Research has focused on how learners engaged in peer review by analyzing the stances of the language functions underlying their interactional or feedback exchanges. Out of the 37 reviewed studies, 30 studies identified and reported various patterns of learners' exploratory interactional feedback exchanges in peer review. However, other seven studies (Guardado \& Shi, 2007; Liang, 2008, 2010; Anderson et al., 2010; Cho \& Cho, 2011; Vorobell \& Kim, 2014; Pham \& Usaha, 2015) were exclusive to the focus areas of learners' interactional exchanges in peer review. Based on our analysis of the findings of these studies, there are three patterns of interactional feedback exchanges: (1) exploratory, (2) procedural and (3) social which are discussed as follows:

Exploratory interactional feedback exchanges This first main category of feedback exchanges reflects learners' interpretation and reflection on their written texts. Thus, out of the 30 studies, the first group of studies $(N=13)$ as summarized in 
Table 1 A Summary of the Patterns of Exploratory Feedback Exchanges in FFPR

\begin{tabular}{|c|c|}
\hline Source & Findings \\
\hline Stanley (1992) & $\begin{array}{l}\text { Advising, eliciting and questioning for evaluators while clarifying, responding to } \\
\text { questions and expressing intended meaning for writers. }\end{array}$ \\
\hline Beason (1993) & $\begin{array}{l}\text { Problem-detecting, advising, altering and describing with advice as the highest } \\
\text { occurred type. }\end{array}$ \\
\hline $\begin{array}{l}\text { Mendonca \& Johnson, } \\
\text { (1994) }\end{array}$ & $\begin{array}{l}\text { Questions such as seeking explanation and comprehension check, explanation of } \\
\text { unclear points, opinion and content, restatement, suggestion and grammar } \\
\text { correction. }\end{array}$ \\
\hline $\begin{array}{l}\text { Mendonca and Johnson } \\
\text { (1994) }\end{array}$ & $\begin{array}{l}\text { Seeking explanation \& checking confirmation, explanation of unclear point, } \\
\text { restatement, providing opinions, suggestions and correction. }\end{array}$ \\
\hline Zhu (1995) & $\begin{array}{l}\text { Questioning, requesting clarifications, responding, providing information, eliciting } \\
\text { feedback, identifying various problems and clarifying intended meaning. }\end{array}$ \\
\hline Lockhart and $\mathrm{Ng}(1995)$ & $\begin{array}{l}\text { Summarizing essays, expressing intention, providing suggestions, evaluation, and } \\
\text { providing information. }\end{array}$ \\
\hline $\begin{array}{l}\text { Villamil and De Guerrero } \\
\text { (1996) }\end{array}$ & $\begin{array}{l}\text { Requesting advice, advising, responding to advice, eliciting, responding to eliciting, } \\
\text { reacting, requesting clarifications, clarifying \& restating. }\end{array}$ \\
\hline $\begin{array}{l}\text { McGroarty and Zhu } \\
\text { (1997) }\end{array}$ & $\begin{array}{l}\text { Seeking clarifications-clarifying, providing information, seeking information \& } \\
\text { providing suggestions. }\end{array}$ \\
\hline $\begin{array}{l}\text { De Guerrero and Villamil } \\
\text { (2000) }\end{array}$ & $\begin{array}{l}\text { Suggestions/advice, subtle hints, elicitations, providing alternatives, instructing or } \\
\text { providing instruction in the form of a mini lesson, defining and using L1. }\end{array}$ \\
\hline Zhu (2001) & Advising, eliciting, questioning, elaborating, hedging, confirming \& justifying. \\
\hline Min (2005) & $\begin{array}{l}\text { Clarifications of intentions, problem-identification, explanation of the nature of the } \\
\text { problem, and offering specific suggestions. }\end{array}$ \\
\hline Lina \& Samuel (2013) & $\begin{array}{l}\text { Correction of errors, providing restatement, using questions, suggestions, repeating, } \\
\text { explanation, confirmation \& identifying errors. }\end{array}$ \\
\hline Hanjani and Li (2014) & $\begin{array}{l}\text { Scaffolding (e.g. instructing, advising) accepting advice, requesting advice, restating, } \\
\text { assessing, question-response (e.g. seeking clarifications), confirming understanding, } \\
\text { persisting, expressing certainty-uncertainty, expressing knowledge-lack of knowledge, } \\
\text { expressing inability, expressing understanding, clarifying, justifying \& responding to } \\
\text { question. }\end{array}$ \\
\hline
\end{tabular}

Table 1 were conducted on FFPR. Patterns of feedback that are exploratory functioned as advising, eliciting and questioning as well as responses to questions and clarifications of information and intended meaning (Stanley, 1992). Other functions are seeking-providing explanations of particular aspects of written texts (Mendonca \& Johnson, 1994; Mendonca \& Johnson, 1994; Min, 2005; Lin \& Samuel, 2013), requesting-providing clarifications (Zhu, 1995; Villamil \& De Guerrero, 1996; McGroarty \& Zhu, 1997; Min, 2005; Hanjani \& Li, 2014), comprehension-check and response (Mendonca \& Johnson, 1994; Hanjani \& Li, 2014) and seeking confirmation and confirming understanding (Mendonca \& Johnson, 1994; Lin \& Samuel, 2013; Hanjani \& Li, 2014).

As learners engaged in FFPR, they sought and provided suggestions or advice on a particular point of text revision, elicited and provided opinions or evaluation (Mendonca \& Johnson, 1994; Mendonca \& Johnson, 1994; Lockhart \& Ng, 1995; Zhu, 1995; Villamil \& De Guerrero, 1996; De Guerrero \& Villamil, 2000; Hanjani \& Li, 2014) and exchanged information (McGroarty \& Zhu, 1997). They also exchanged restatement, grammar corrections (Mendonca \& Johnson, 1994; Mendonca \& Johnson, 1994), identfied problems in their texts (Beason, 1993; Zhu, 1995; Min, 2005; Lin \& Samuel, 2013), summarized points, expressed intentions (Lockhart \& $\mathrm{Ng}, 1995)$ and decribed various aspects of texts (Beason, 1993) and restating or repeating (Lin \& Samuel, 2013; Hanjani \& Li, 2014). 
The exploratory functions of peer feedback also underlie how the learners engaged in instructing in the form of a mini lesson (Villamil \& De Guerrero, 1996; De Guerrero \& Villamil, 2000; Hanjani \& Li, 2014), subtle hints, providing options/alternatives, defining and using L1 to assist each other in attending to the problems and solving them (De Guerrero \& Villamil, 2000; Hanjani \& Li, 2014). In FFPR, learners exchanged comments that functioned as elaborating, (Zhu, 2001), referencing, guessing, expressing knowledge/lack of knowledge, expressing inability and persisting (Hanjani \& Li, 2014).

The second group of studies $(N=17)$ in Table 2 applied various technological tools, including synchronous and asynchronous tools to peer review in writing. The increasing applications of CAPR have motivated many researchers to explore learners' interactional feedback exchanges. The results of our review indicate that CAPR engaged ESL learners in various exploratory feedback exchanges. The most commonly identfied functions of

Table 2 A Summary of the Patterns of Exploratory Feedback Exchanges in CAPR

\begin{tabular}{|c|c|}
\hline Source & Findings \\
\hline $\begin{array}{l}\text { Sullivan and Pratt } \\
\text { (1996) }\end{array}$ & Turn taking: positive comment \& suggestions for revision. \\
\hline $\begin{array}{l}\text { Di Giovanni and } \\
\text { Nagaswami (2001) }\end{array}$ & $\begin{array}{l}\text { (1) Questioning: requesting such as checking comprehension, and requesting } \\
\text { suggestions (5\%), (2) explanation such as opinions, agreement and } \\
\text { disagreement (7\%), (3) restatement }(21 \%) \&(4) \text { suggestion }(24 \%) \text {. }\end{array}$ \\
\hline $\begin{array}{l}\text { Liu and Sadler } \\
\text { (2003) }\end{array}$ & Suggestion (19.3\%), evaluation (25.79\%), alteration (46.8\%) and clarification (8.9\%). \\
\hline Tuzi (2004) & Advising, questions (requests), statements, alternatives and criticism. \\
\hline Jones et al. (2006) & $\begin{array}{l}\text { Initiating moves: offering, stating and questioning and responding moves: } \\
\text { clarifying, confirming, accepting, rejecting, compliance and acknowledging } \\
\text { moves. }\end{array}$ \\
\hline Hewett (2006) & Informing, directing attention, eliciting peers' opinions and offering suggestions. \\
\hline $\begin{array}{l}\text { Liou and Peng } \\
\text { (2009) }\end{array}$ & Suggestion (25/21.6\%), evaluation (33/28.4\%) and clarification (4/3.4\%). \\
\hline $\begin{array}{l}\text { Ho and Usaha } \\
\text { (2009) }\end{array}$ & $\begin{array}{l}\text { Evaluation, clarification, alteration, suggestion/advice, explanation, confirmation } \\
\text { and statement with clarification }(29.5 \%+27.36 \%) \text { and suggestion/advice }(29.02 \% \\
+26.42 \%) \text { as the highest in both sessions. }\end{array}$ \\
\hline $\begin{array}{l}\text { Song and Usaha } \\
(2009)\end{array}$ & $\begin{array}{l}\text { Question (18.0\%), suggestion (15.4\%), criticism (14.9\%), and evaluation (13.5\%) } \\
\text { while the least are explanation (8.7\%), clarification (6.2\%) and restatement (4.5\%). }\end{array}$ \\
\hline $\begin{array}{l}\text { Cha and Park } \\
(2010)\end{array}$ & $\begin{array}{l}\text { Openings, closing, statements, questions including requests, responses, suggestions, } \\
\text { opinions, correction \& topic. The number of such categories varied from the lowest } 52 \\
\text { to the highest } 437 .\end{array}$ \\
\hline Ho (2010) & $\begin{array}{l}\text { Suggestion/advice (10.3\%), clarification (9.3\%) confirmation }(4.7 \%) \text { and evaluation } \\
(4.3 \%) \text {, alteration, statement and explanation (4\%, 3.3\% and } 2.9 \% \text {, respectively). }\end{array}$ \\
\hline $\begin{array}{l}\text { Ho and Usaha } \\
\text { (2011) }\end{array}$ & $\begin{array}{l}\text { Suggestion/advice }(27.5 \%) \text {, clarification }(23.6 \%) \text { confirmation }(12.8 \%) \text { and evaluation } \\
(12.3 \%) \text {, alteration, statement and explanation }(9 \%, 8.6 \% \text { and } 6.2 \% \text {, respectively). }\end{array}$ \\
\hline Chang (2012) & $\begin{array}{l}\text { Suggestion, evaluation, alteration and clarification with different percentages (64\% } \\
\& 23 \%),(5 \% \text { \& } 1 \%),(19 \% \& 5 \%) \text { and }(13 \% \text { \& } 70) \text { for evaluation, clarification, suggestion } \\
\text { and alteration in both synchronous and asynchronous CAPR. }\end{array}$ \\
\hline Bradley (2014) & Suggestion (120) followed by evaluation (114), alteration (48) and clarification (32). \\
\hline $\begin{array}{l}\text { Razak and Saeed } \\
(2014)\end{array}$ & $\begin{array}{l}\text { Seeking clarifications \& confirmation check), justifying and scaffolding: definitions } \\
\text { and using L1. }\end{array}$ \\
\hline Ho (2015) & $\begin{array}{l}\text { In both review sessions, suggestion }(71 / 37 \% \text { \& } 90 / 48 \%) \text {, evaluation }(54 / 28 \% \& 37 / \\
20 \%) \text {, clarification }(24 / 12 \% \text { \& } 12 / 6 \%) \text {, alteration }(14 / 7 \% \text { \& } 17 / 9 \%) \text { and other }(5 / 4 \% \text { \& } \\
17 / 9 \%) \text { while the least frequently posted commenting type was response }(3 / 2 \% \text { \& } \\
13 / 7 \%) \text {. }\end{array}$ \\
\hline $\begin{array}{l}\text { Saeed and Ghazali } \\
(2016)\end{array}$ & $\begin{array}{l}\text { Identifying problems, evaluating, agreements and disagreements, clarifications, } \\
\text { suggestions, seeking for clarifications, justifications, confirming and lack of } \\
\text { understanding. }\end{array}$ \\
\hline
\end{tabular}


such feedback are questions that seek peers' clarifications, justifications, confirmation and opinions and providing suggestions or advice on particular aspects of their texts (Sullivan \& Pratt, 1996; Di Giovanni \& Nagaswami, 2001; Liu \& Sadler, 2003; Tuzi, 2004; Hewett, 2006; Jones et al., 2006; Liou \& Peng, 2009; Song \& Usaha, 2009; Cha \& Park, 2010; Ho, 2010; Ho \& Usaha, 2013; Chang, 2012; Bradley, 2014; Razak \& Saeed, 2014; Ho, 2015; Saeed \& Ghazali, 2016). Other exploratory patterns of peer feedback exchanges are evaluations of various aspects of written texts, clarifications, alterations (Liu \& Sadler, 2003; Liou \& Peng, 2009; Ho, 2010; Ho \& Usaha, 2013; Chang, 2012; Bradley, 2014; Ho, 2015; Saeed \& Ghazali, 2016), agreement and disagreement (Di Giovanni \& Nagaswami, 2001; Saeed \& Ghazali, 2016), acceptance and rejections of peers' revisions (Jones et al., 2006).

It is also interesting that ESL/EFL learners exchange exploratory feedback functioning as statements or explanation (Tuzi, 2004; Jones et al., 2006; Ho \& Usaha, 2009; Ho, 2010; Cha \& Park, 2010; Ho \& Usaha, 2013), restatements (Di Giovanni \& Nagaswami, 2001), justification (Razak \& Saeed, 2014; Saeed \& Ghazali, 2016), criticism (Tuzi, 2004; Song \& Usaha, 2009), complying, acknowledging (Jones et al., 2006), informing, directing attention (Hewett, 2006), correction (Cha \& Park, 2010) and scaffolding in the form of definitions and use of L1 (Razak \& Saeed, 2014).

From the reviewed studies that identified the various functions of peer exploratory feedback in CAPR, some studies also reported the frequency occurrence of these patterns of feedback. The results indicate that the most frequently patterns of peer exploratory feedback exchanges varied from alterations (Liu \& Sadler, 2003), opening moves (Cha \& Park, 2010), only suggestions (Ho, 2010; Bradley, 2014; Ho, 2015) to a combination of suggestions and other patterns such as restatements (Di Giovanni \& Nagaswami, 2001), evaluation (Liou \& Peng, 2009), clarifications (Ho \& Usaha, 2009) and questions (Song \& Usaha, 2009).

Procedural interactional exchanges The second main category of interactional exchanges in terms of the language functions comprises those procedural comments that are exchanged by learners as means to organizing the process of peer review. Examples of procedual comments are pointing at particular parts of texts (Stanley, 1992; Zhu, 2001; Jones et al., 2006) and announcing various aspects of the task (Stanley, 1992; Villamil \& De Guerrero, 1996; Zhu, 2001). Other patterns of procedural feedback exchanges, as identified by Hanjani and Li (2014), are providing directives to peers, asking them to read parts of the texts, assigning responsibilities and clarifying instructions. However, the occurrence of such procedural interactional exchanges seemed to be low in these previous studies.

Social interactional exchanges The third main category of interactional exchanges in terms of the language functions encompasses those social interactional comments as a means to establish a positive atmosphere in peer review (Beason, 1993; Di Giovanni \& Nagaswami, 2001; Tuzi, 2004; Jones et al., 2006; Song \& Usaha, 2009; Cha \& Park, 2010; Hanjani \& Li, 2014). Examples of these comments are thanking, welcoming, praising and even social chatting or talks. Others are greeting, thanking and welcoming, confusion, surprise, blaming, laughing and distraction (Hanjani \& Li, 2014). 
Thus, the above various patterns of learners' interactional feedback exchanges in terms of the language functions are synthesized and illustrated in Fig. 1. The first category of interactional feedback exchanges is exploratory in nature since it is an indicator of learners' reflection on the task of peer review. It is scaffolding and non-scaffolding.

For the scaffolding sub-category, few studies identified scaffolding patterns such as seeking-providing advice, exchanging suggestions, instructing in the form of a mini lesson on a certain aspect of their texts, defining, using L1 and suggesting or advising (De Guerrero \& Villamil, 2000; Hanjani \& Li, 2014). Such scaffolding comments are

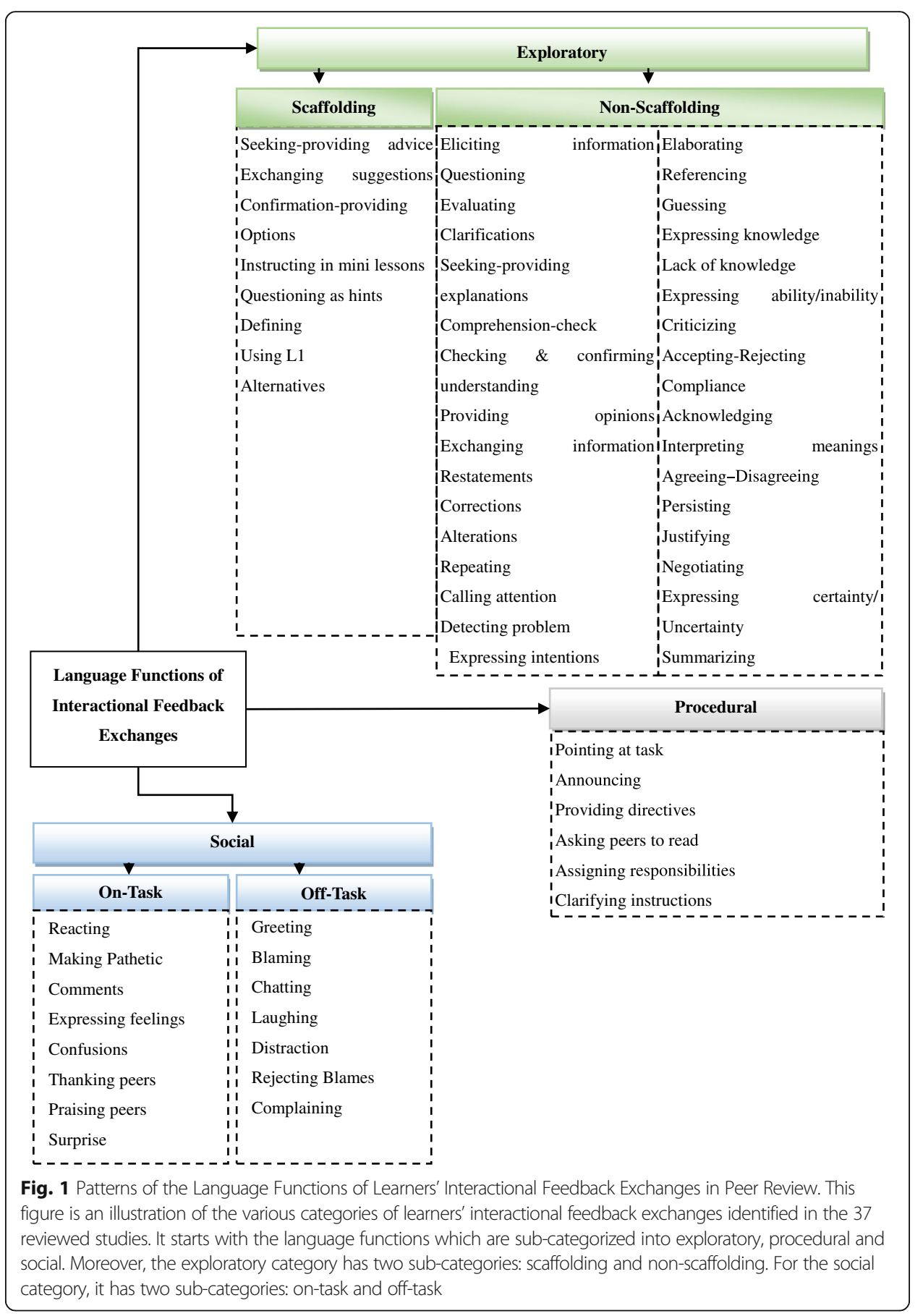


intended to verbally assist peers to solve problems in their writing within the ZPD. Based on their findings, those recent proponents of Vygotsky's (1978) socio-cultural theory also supported the mutual or reciprocal nature of scaffolding exchanges in their studies. In other words, these few studies stated above proved that scaffolding is not a necessarily unidirectional type of assistance from an expert to a novice learner, but it can be also a bidirectional verbal support provided and received reciprocally by two or more novice learners in collaborative writing, including peer review.

The non-scaffolding sub-category comprises many patterns of language functions of learners' peer feedback, including explanation, clarification, summarizing, elaboration, restatement, interpretation of certain aspects of written tasks, expressing intended meanings and others. Although such feedback exchanges may not be scaffolding in the sense that they do not function as language or verbal assistance in enabling peers to target problems and solve them in their written tasks. Yet, they show how learners attempt to express their intended meanings and ideas, elaborate them, interpret them and even sum up points.

The second category of learners' interactional exchanges in peer review is procedural because it shows how learners attempt to carry out the process of peer review, handle the task of peer revision, organize their interaction in peer review and distribute their tasks in peer review. In addition, based on our categorization, the third sub-category of feedback exchanges, social interaction, is classified into two sub-types: on-task and offtask interactional exchanges. The on-task social interactional exchanges illustrate how learners praise one another in peer review, react to their feedback, thank and welcome one another, and even express feelings such as confusion and surprise. The off-task social interactional exchanges, however, function as greetings, joking, distraction, laughing, blaming and rejecting blames. Thus, they are irrelevant to the task because they reflect how learners engage in social matters in peer review.

\section{The focus areas of interactional feedback exchanges in peer review}

Studies have gone beyond this mere categorization of patterns of interactional comments by looking at the focus areas/scope of interaction. Out of the 37 reviewed studies, only 23 studies identified and reported the nature and focus areas of ESL/EFL learners' interactional feedback exchanges in peer review. These are discussed under the following two main categories coded and clustered in the current review:

Revision-related/oriented interactional comments This first main category comprising revision-oriented exchanges shows how ESL/EFL learners remain on the task and target various problems in their written texts. Regarding this, five studies identified the focus areas of revision-oriented feedback in FFPR as in Table 3. Four of these studies (Beason, 1993; Lockhart \& Ng, 1995; Min, 2005; Vorobel \& Kim, 2014) indicated that peer feedback focused on issues of writing at the macro-level, such as idea development, organization and purpose more than issues at the micro level, such as mechanics and grammar. On the other hand, Hanjani and Li (2014) reported that most of EFL learners' interactional exchanges focused on micro-level issues such as grammar, while a few comments focused on macro-level issues such as content and organization. This was ascribed to learners' proficiency levels in English which could not have allowed some of them to target macro-level issues in writing. 
Table 3 A Summary of the Revision-Oriented Feedback Exchanges in FFPR and CAPR

\begin{tabular}{|c|c|}
\hline Source & Findings \\
\hline Beason (1993) & $\begin{array}{l}\text { Micro- (focus, organization and development of ideas and macro-(focus, } \\
\text { organization and development of ideas across multiple paragraphs) more } \\
\text { than surface features (mechanics \& grammar). }\end{array}$ \\
\hline $\begin{array}{l}\text { Lockhart and } \mathrm{Ng} \\
\text { (1995) }\end{array}$ & Focus: Process, ideas, audience and purpose. \\
\hline Min (2005) & $\begin{array}{l}\text { EFL learners generated a higher number of comments on the global features } \\
\text { of texts }(53 \% \text { \& 57\%) than those comments focusing on local features }(47 \% \\
\& 43 \%) .\end{array}$ \\
\hline $\begin{array}{l}\text { Vorobel and Kim } \\
\text { (2014) }\end{array}$ & $\begin{array}{l}\text { Global aspects of their texts such as organization of ideas, consistency of ideas } \\
\text { and clarity of ideas and local aspects of texts including form-based issues as } \\
\text { vocabulary, using information from L1 sources in L2 writing, and mechanics } \\
\text { such as punctuation and formatting. }\end{array}$ \\
\hline $\begin{array}{l}\text { Sullivan and Pratt } \\
\text { (1996) }\end{array}$ & More comments on the task of criticizing the writing. \\
\hline $\begin{array}{l}\text { Di Giovanni and } \\
\text { Nagaswami (2001) }\end{array}$ & $\begin{array}{l}\text { Global aspects of texts such as ideas and organization of ideas more than FFPR } \\
\text { interactions. }\end{array}$ \\
\hline $\begin{array}{l}\text { Liu and Sadler } \\
\text { (2003) }\end{array}$ & $\begin{array}{l}\text { More global comments on idea development, organization, audience and purpose, } \\
\text { than local comments on wording, grammar and punctuations. }\end{array}$ \\
\hline Jones et al. (2006) & More comments on content, organization, topic and thesis of writing. \\
\hline Hewett (2006) & $\begin{array}{l}\text { Most comments on writing processes, thesis statements, ideas and organization, } \\
\text { whereas least on formal aspects of their texts such as grammar, mechanics and } \\
\text { others }\end{array}$ \\
\hline $\begin{array}{l}\text { Guardado and Shi } \\
\text { (2007) }\end{array}$ & $\begin{array}{l}\text { More comments on thesis statement, topic sentences, unity, content and } \\
\text { coherence. }\end{array}$ \\
\hline $\begin{array}{l}\text { Liou and Peng } \\
\text { (2009) }\end{array}$ & $\begin{array}{l}\text { More revision oriented comments than non-revision-oriented comments after } \\
\text { training. }\end{array}$ \\
\hline $\begin{array}{l}\text { Ho and Usaha } \\
\text { (2009) }\end{array}$ & $\begin{array}{l}\text { Most revision-related comments on content, followed by organization, grammar } \\
\text { and vocabulary, while the least attention was paid to mechanics. }\end{array}$ \\
\hline $\begin{array}{l}\text { Anderson et al. } \\
\text { (2010) }\end{array}$ & $\begin{array}{l}\text { Of Chalmers students' (77) revision-oriented comments in asynchronous peer } \\
\text { review, more focused on content (47) than language ( } 30) \text { while of Miami } \\
\text { students' (74) revision-oriented comments, more focused on language (42) } \\
\text { than content (32). }\end{array}$ \\
\hline Cha and Park (2010) & In each pair, almost $50 \%$ of their interaction focused on their essays. \\
\hline Ho (2010) & More global-oriented feedback than local ones. \\
\hline Liang $(2008,2010)$ & $\begin{array}{l}\text { In (2008), meaning negotiation, error correction, task management, and technical } \\
\text { action were used less than other patterns among the six small groups. In 2010, } \\
\text { social talk, task management, and content discussion outnumbered interactions } \\
\text { on meaning negotiation and error correction. }\end{array}$ \\
\hline Ho and Usaha (2011) & 1060 (58.43\%) global comment and 754 (41.56\%) local comments. \\
\hline Chang (2012) & $\begin{array}{l}\text { In the asynchronous CAPR, more local comments in both tasks, while in the } \\
\text { synchronous CAPR, the global and local comments were balanced. }\end{array}$ \\
\hline Bradley (2014) & $\begin{array}{l}\text { More global revision-oriented comments (250/80\%) than local revision-oriented } \\
\text { comments }(64 / 20 \%) \text {. }\end{array}$ \\
\hline Ho (2015) & More global comments than local comments. \\
\hline $\begin{array}{l}\text { Pham and Usaha } \\
\text { (2015) }\end{array}$ & $\begin{array}{l}\text { After training, a higher number of global revision-oriented comments }(552 / 60.2 \%) \\
\text { than local revision-oriented comments (365/39.8\%). }\end{array}$ \\
\hline $\begin{array}{l}\text { Saeed and Ghazali } \\
\text { (2016) }\end{array}$ & More comments on content and meaning. \\
\hline
\end{tabular}

Concerning the CAPR mode, there are 18 studies that identified the focus areas of learners' revision-oriented interactional comments. Findings of most previous studies support the role of peer feedback identifying macro-level or global issues of writing, including the task of criticizing writing (Sullivan \& Pratt, 1996), ideas or content (Di Giovanni \& Nagaswami, 2001; Hewett, 2006; Jones et al., 2006; Anderson et al., 2010; Saeed \& Ghazali, 
2016), organization (Di Giovanni \& Nagaswami, 2001; Hewett, 2006; Jones et al., 2006), thesis statements (Hewett, 2006; Jones et al., 2006; Guardado \& Shi, 2007), topic (Jones et al., 2006; Guardado \& Shi, 2007), writing processes (Hewett, 2006) unity and coherence (Guardado \& Shi, 2007) as well as essay improvement (Cha \& Park, 2010).

Other studies obtained results that corroborate the higher percentage of peer feedback in the revision-related discourse (Ho \& Usaha, 2009; Liang, 2008, 2010). In these three studies, the revision-oriented discourse refers to peer feedback that focuses on content, meanings and error correction as in Liang $(2008,2010)$ and content, organization, grammar, vocabulary and mechanics as in Ho and Usaha's (2009) study. While Liang (2008) found that content discussion scored the highest among all types of focus areas, Liang (2010) found that interaction on task management, and content outnumbered meaning negotiation and error correction. According to Ho and Usaha (2009), feedback focusing on content scored the highest percentage, followed by organization, grammar and vocabulary. However, the least attention was paid to mechanics.

Some previous researchers (Liou \& Peng, 2009; Ho, 2010, Ho \& Usaha, 2013; Bradley, 2014; Ho, 2015; Pham \& Usaha, 2015) used Liu and Sadler's (2003) taxonomy of the nature and focus areas of peer feedback. In terms of the nature of peer feedback, it is classified as revision-oriented and non-revision-oriented. For the focus areas, the revision-oriented comments focus on the global aspects of texts (idea development, organization of ideas, purpose and audience) and local aspects of texts (wording, grammar and punctuations). The results of these studies indicate that learners engaged more in revision-oriented feedback than non-revision-oriented feedback. More interestingly, the same researchers found that learners made a higher number of global revisionoriented comments than the local revision-oriented comments. Such results are similar to the results in in Liang $(2008,2010)$ in respect to the higher number of revisionoriented comments, but those comments leading to text revisions in Liang's studies were classified into different focus areas: content, meanings and errors. Nevertheless, the results of both studies by Liang $(2008,2010)$ still support the role of synchronous feedback interactions in facilitating learners' attention to content more than meanings and grammar errors. Yet, this contradicts results of other two studies Anderson et al., 2010 \& Chang, 2010) showing that learners produced a higher number of local comments focusing on the language issues.

From the above discussion of the findings of studies on CAPR, it is apparent that CAPR assists learners in generating more feedback that is oriented towards revisions and that more feedback focuses on macro-level or global issues, including content, organization and purpose than local issues of writing, including language and mechanics. Yet, while some researchers support the role of synchronous CAPR (Liu \& Sadler, 2003; Hewett, 2006; Jones et al., 2006; Liang, 2008, 2010; Anderson et al., 2010; Cha \& Park, 2010; Ho, 2010; Chang, 2012), other researchers (Sullivan \& Pratt, 1996; Liou \& Peng, 2009; Ho \& Usaha, 2013; Bradley, 2014; Ho, 2015; Pham \& Usaha, 2015; Saeed \& Ghazali, 2016) support the role of asynchronous CAPR in facilitating learners' feedback towards more global issues in writing.

Non-revision-related/oriented interactional comments The second main category of feedback exchanges in terms of the focus areas, known as non-revision-oriented 
ineractional comments, encompasses these comments that do not target any problems in learners' written texts in peer review. However, most previous studies reported only calculations of ESL/EFL learners' comments in the non-revision-oriented discourse or social space without identifying their focus areas (Liu \& Sadler, 2003; Liou \& Peng, 2009; Ho, 2010; \& Usaha, 2013; Ho, 2015; Pham \& Usaha, 2015). Negligence of identification of the focus areas of this category of comments could be due to the fact that such comments do not target any problems in writing.

Only a few studies have identified the focus areas of the non-revision-oriented interactional exchanges which are establishing positive tones that sugar coated the criticism carried out in the follow-up-negative comments (Guardado \& Shi, 2007), thanking and praising to alleviate their critical tone and establish relationships (Hanjani \& Li, 2014) and creating an atmosphere of sugar-coating the criticism in their revision-oriented comments (Bradley, 2014). In the CAPR mode (Darhower, 2002; Fitze, 2006; Jones et al., 2006; Cha \& Park, 2010; Liang, 2010), such comments reflect the socio-relational aspect of communication, such as talking about irrelevant matters and establishing a sound social context for maintaining friendship as well as appraisal and encouragement (Anderson et al., 2010).

From the above findings, peer review helps ESL/EFL learners to exchange various patterns of feedback: exploratory, procedural and social. Moreover, it engages learners more in revision-oriented feedback that targets issues in their written texts. Especially with the use of synchronous and asynchronous tools, learners become less shy of their peers and more confident to offer more revision-oriented feedback that focuses on more global issues. Although this particular investigation in previous studies enriches our understanding of the value of peer feedback in writing, peer feedback can be more valuable if learners integrate such feedback in improving their writing. Therefore, some previous studies discussed in the next section of the review have looked at whether learners incorporate their peer feedback in revising their writing.

\section{Is there empirical evidence of learners' incorporation of peer interactional feedback exchanges in their text revisions?}

There are some studies that have looked at whether peer feedback exchanges were efficacious in enhancing learners' written texts. For instance, Beason (1993) reported that only 156 comments out of the overall 233 comments resulted into 117 text revisions. Similarly, Mendonca and Johnson (1994) showed that although students used their peers' comments to revise their essays, they incorporated peer feedback comments in their text revisions selectively, thus deciding what to revise in their own texts. According to Tuzi (2004), learners integrated peer feedback from the asynchronous CAPR into clause, sentence and even paragraph-level revisions more than the FFPR feedback.

In comparing between the initial and revised drafts to identify those text revisions based on peer's feedback, Guardado and Shi (2007) found that only 13 out of 22 students revised their drafts, and out of the 13 students, 10 students revised their drafts based on their peers' online feedback, while 3 of them made self-generated revisions. Out of the 10 students, 4 of them made major revisions, whereas 3 of them made minor revisions. In other words, only 13 student-writers accepted 27 feedback 
comments out of the total number of 60 feedback comments in revising their texts accordingly, whereas the other 9 student-writers almost ignored their peers' feedback. This was attributed to their cultural and educational backgrounds and uncertainty about the accuracy and reliability of their peers' feedback comments.

According to Liou and Peng (2009), learners' incorporation of the asynchronous interactional comments in their text revisions was not high due to their unwillingness to revise the texts based on peer feedback comments. Pham and Usaha (2015) found that learners used peer feedback in revising sentences in their texts. In contrast, the revisions made by the learners based on self-decisions are at word and phrase-levels. Yet, these last two studies did not provide any evidence showing the feedback interactionrevision connections. According to Song and Usaha (2009), in the FFPR peer review, out of the total revision-oriented comments $(n=364), 292$ comments were incorporated into subsequent text revisions. On the other hand, in the asynchronous and synchronous CAPR peer review mode, out of the total revision-oriented comments $(N=$ 300), 257 comments were integrated into learners' text revisions.

Cha and Park (2010) used a quantitative measure to find out the extent to which learners incorporated their peers' opinions or ideas in revising their essays. The results indicated that the amount or percentage of interactional exchanges incorporated in their text revisions varied among the 14 pairs of learners. In Ho's (2010) study, lower level-revisions, including phrase and words were made by learners themselves rather than based on peers' feedback exchanges. However, higher-level revisions, such as sentences and paragraphs were made based on their peers' feedback. Thus, the quantitative analysis showed that $39 \%$ of revisions were triggered by peer feedback and $61 \%$ were made by the student writers based on their own decisions.

Finally, there are only two studies which have used textual analyses to determine the extent to which learners incorporate online peer feedback exchanges into revising their texts. The first study by Hewett (2006) indicated that learners incorporated most of the synchronous CAPR feedback exchanges into their text revisions. Yet, this study did not provide any evidence of the connections between the feedback exchanges and the text revisions. The second study by Liang (2010) provided evidence of how EFL learners integrated synchronous interactions into their text revisions, thus concluding that synchronous interactions facilitated their text revisions. However, the rate of synchronous comments integrated into learners' text revisions differed among the groups of learners according to the tasks, which is discussed below as one factor affecting interactions and text revisions in peer review.

\section{What are the major factors affecting ESL/EFL learners' interactional feedback exchanges in peer review?}

The review of previous related research identified various factors affecting learners' interactional feedback exchanges in peer review. These factors are discussed in the following sections:

\section{Training and instruction on feedback}

Several previous studies reported the effect of training learners through explicit instruction on their interactional feedback exchanges in peer review. In these reviewed studies, learners were trained on peer review through explicit instruction provided by instructors 
who are often the researchers. Such instruction guides learners on aspects of writing that they should focus on and how to provide feedback on such issues of writing. Usually, this instruction as developed by researchers should be clear and consistent with the purpose of the study and aims of writing courses at the university. For instance, Stanley (1992) reported that training affects the intensity of interaction as the coached or trained groups interacted more than the untrained groups. Moreover, groups who received coaching offered more specific interactional comments to their peers that helped them to revise their texts better. This implies that training enabled those coached groups to assume the roles as evaluators. Evidences of the increased engagement of the coached groups are the higher incidences of interactional exchanges: pointing, advising and collaborating as well as clarifying.

Similarly, Zhu (1995) reported that the coached learners engaged more actively in peer review than the uncoached group. Moreover, the negations of the trained group were more extensive, more in depth and characterized by extended exchanges on a particular topic, suggesting lovelier and richer discussions. Similarly, McGroarty and Zhu (1997) found that the trained group engaged more extensively as evidenced by the higher number of turns and more extended and livelier interactions than the untrained group. The findings of Min's (2005) study indicated that training through explicit instruction on peer review enabled learners to generate significantly more comments which revolved around clarifying, identifying and expounding a single issue as well as suggesting how to improve their texts. It also increased learners' focus of comments as they made more comments on global issues. Other two studies showed conflicting results. For instance, Liou and Peng (2009) showed that training did not increase the learners' willingness to incorporate peers' comments in revising their texts.

\section{Mode of peer review}

The analysis of the findings of some previous studies (Sullivan \& Pratt, 1996; Di Giovanni \& Nagaswami, 2001; Liu \& Sadler, 2003; Jones et al., 2006; Song \& Usaha, 2009, Chang, 2012; Ho, 2015) on learners' interactional feedback exchanges showed that the mode of peer review has a significant effect on learners' feedback. All these studies combined and compared between FFPR and CAPR in relation to learners' feedback exchanges. For the CPRA, five of these studies used both synchronous and asynchronous tools (Di Giovanni \& Nagaswami, 2001; Liu \& Sadler, 2003; Song \& Usaha, 2009; Chang, 2012; Ho, 2015), whereas two of them employed only synchronous tools, such as chats (Sullivan \& Pratt, 1996; Jones et al., 2006).

Interesting findings were obtained by these studies, showing several differences between FFPR and CAPR in terms of the functions of feedback, focus areas of feedback, incorporation of peer feedback in writing, and other aspects related to roles of learners in interaction. For the functions of peer feedback, first, the number of negotiations in FFPR was higher than that of negotiations in the CAPR (Di Giovanni \& Nagaswami, 2001). This is because of the conversational mode of communication in FFPR. Turntaking in the FFPR mode was also found to be greater than that in the asynchronous CAPR as in the latter mode of peer review, it took longer time to type the comments (Sullivan \& Pratt, 1996). Similarly, Song and Usaha (2009) found that the number of the language functions of learners' feedback exchanges in the FFPR was higher than 
that of feedback in the CAPR mode. However, results of Liu and Sadler (2003) contradict this as the researchers reported that in terms of the patterns of language functions of comments, the number was higher for CAPR than that in the FFPR. Moreover, while suggestion was the highest in the FFPR mode, alteration was the highest in the CAPR.

For the nature and focus areas of feedback in FFPR vs. CAPR, results support CAPR. First, learners' turn taking tends to be more critical and focused in the CAPR as evidenced by the sequence of comments: positive comments followed by suggestions (Sullivan \& Pratt, 1996). Evidence also indicates that learners' negotiations in the CAPR allowed students to reflect and remain focused on the task (Di Giovanni \& Nagaswami, 2001). This seems similar to results of Liu and Sadler (2003), indicating that the learners exchanges more feedback in the CAPR mode than in the FFPR. Moreover, leaners' feedback exchanges in the synchronous CAPR mode tended to focus more on global issues in writing, including content, organization and process, whereas in the FFPR, feedback was found to be more local since it focused on grammar, vocabulary, and style (Jones et al., 2006). According to Liu and Sadler (2003) and Ho (2015), the number of learners' feedback that focused on local issues in writing: wording, grammar, and punctuation in the CAPR mode was higher than that of feedback in the FFPR mode.

Results of the above studies indicate that CAPR is not totally better than FFPR or vice versa, but it provides learners with opportunities to explore and discuss global issues of texts. In other words, learners have sufficient time to reflect on their writing and think of global issues in the CAPR as opposed to the FFPR where interaction tends to be more simultaneous and learners cannot have time to think of such issues (Jones et al., 2006). In the CAPR, learners can also detect more local issues in texts and consequently comment more on such issues. However, in the FFPR mode, these lower local comments could be attributed to the lack of such functions and students' lack of confidence regarding their grammar and spelling (Liu \& Sadler, 2003).

On the other hand, there are studies which reported results contradicting the above results regarding learners' higher number of feedback in terms of focus areas. For instance, Ho (2015) reported that the number of global feedback that focused on content, organization and purpose in the FFPR mode was higher than that of global feedback in the CAPR mode. Chang (2012) found also differences in the number of feedback not only between FFPR and CAPR modes, but also between synchronous and asynchronous modes. The researcher found that in both FFPR and synchronous CAPR modes, the learners produced a higher number of global feedback than they did in the asynchronous CAPR mode. This was attributed to the delayed time in the asynchronous CAPR mode. In other words, when learners engaged in asynchronous CAPR, they had time to delay their responses, which made their peers shift the focus of their feedback from global issues to local issues.

In relation to incorporation of peer feedback, one study reported that the mode of peer review affects the percentage of learners' integration of peer feedback into their writing (Song \& Usaha, 2009). This study reported that the higher rate of feedback comments incorporated into learners' text revisions in the CAPR mode implies that, as opposed to the FFPR mode where feedback comments are oral, in the CAPR, the comments are written and learners have enough time to read and understand them well 
and consequently, integrate their peers' suggestions into their text revisions. Finally, concerning learners' roles in interaction, Sullivan and Pratt (1996) found that while in the FFPR, the author talked more, thus dominating the discourse, in CAPR, the author talked less, thus equalizing participation among all members.

\section{Type of written tasks in peer review}

There are a few studies showing that the type and number of learners' feedback exchanges differed according to the tasks being revised. In this regard, Liou and Peng (2009) found that the number of commenting patterns in the first assignment was different from the fourth assignment. The researchers reported that there was an increase in the number of comments, especially suggestions and evaluations in the fourth assignment. Moreover, the revision-oriented comments increased and there was an increase in the global-oriented comments. It was attributed to the the difficulty in the writing tasks in both assignments.

EFL learners' synchronous interaction facilitated their text revisions, though this differed among the groups of learners according to the tasks (Liang, 2010). In the book review, two groups integrated most of their content-related interactions into their text revisions, while for the research paper revision, only a very small proportion of text revisions were linked to learners' interaction as the learners made most text revisions based on their own decisions and other interactional processes such as social interactional comments. Ho (2015) found that the mode of peer review is not the only factor that contributed to the differences in the number and percentage of commenting patterns, but the nature of the task was also seen as an important factor behind this. Whereas in the first task, the global and local comments accounted for ( $N=311 \& 175$, respectively), in the second task, the global and local comments accounted for $(N=479 \& 132)$.

\section{Learners' roles in peer review}

Regarding learners' role: whether they are reviewers or writers, it has been demonstrated as an important factor affecting their interactional feedback exchanges in peer review. According to Mendonca and Johnson (1994), most of the negotiations were initiated by student-reviewers. Such result indicates that since the learner-reviewers were not well familiar with the content of the written texts, they tended to initiate negotiations that sought explanations or clarifications from their peer-writers. Moreover, the functions and numbers of interactional feedback exchanges differed according to the reviewer-writer roles. For instance, reviewers were observed to produce more feedback exchanges by which they explained and gave their opinions on the clarity of ideas in writing.

Finally, Zhu's (2001) results indicated that when ESL learners acted as writers, they produced fewer turns and responded to peer feedback, but they did not clarify their writing for the readers (native speakers). Acting as readers, the ESL students generated a similar amount of oral interactional exchanges, but they encountered difficulties competing for turns and sustaining and regaining them when they were interrupted by the writers. These results implied that the ESL students were at somewhat of a disadvantage when interacting with the native speakers in oral peer review and raise some concerns about ensuring equality in mixed peer response groups. 


\section{Learners' levels of English proficiency}

Another important factor influencing learners' types and frequency of interactional feedback exchanges is learners' level of proficiency in English. There are only two previous studies which measured the effect of this factor by comparing the interactional feedback exchanges among learners with different levels of English proficiency. Zhu (2001) reported that the language functions of the ESL learners' interactional exchanges in mixed peer review were restricted compared to those of the native speakers. It was found that while the functions of the exchanges produced by the ESL learners were mostly announcing, reacting, questioning, advising, and justifying, those exchanges of the native speakers were confirming, pointing, hedging, elaborating, and eliciting. Thus, it was concluded that while the native speakers tended to provide suggestions more directly through advising, the ESL learners tended to point out at and question problematic areas.

The level of English proficiency was observed by Hanjani and Li (2014) to affect the interaction of learners, especially in asymmetrical pairs of learners in peer review. In such asymmetrical pairs, it was noticed that the more competent learner acted as a tutor who seemed to be confident, initiated the interaction and called the attention of the less competent peer to the problems in the written tasks. However, the less competent peer seemed to be more conservative, less confident, thus, changing the advice and receiving feedback from the more competent.

\section{Other factors}

There are also other three factors that affect learners' interactional exchanges in peer review, two of which are gender and configuration of peer review dyads that were identified and reported in two different studies, while the third factor, context of peer review, was analyzed by us. Concerning the gender factor, Hanjani and Li (2014) shed light on the effect of gender on interaction dynamics based on their observation. It was observed that in mixed gender pairs of learners, the interaction seemed more polite, reverent, and formal and no disapproval even in cases of disagreements. However, in single gender pairs, the interaction looked more natural and more dynamic, and the learners produced more interaction, interrupted each other more often, used more informal language and more frequently challenged each other. For the configuration of peer review dyads, Mendonca and Johnson (1994) found that peer review dyads from different fields of study generated more negotiations that peer review dyads of the same field of study.

Regarding the factor of peer review context, there are several interesting findings generated from our comparison of the contexts of peer review in the 37 studies. First, most of the studies reviewed in this paper $(N=26)$ have been conducted among ESL learners (Stanley, 1992; Beason, 1993; Mendonca \& Johnson, 1994; Lockhart \& Ng, 1995; Zhu, 1995; Mendonca \& Johnson, 1994; Sullivan \& Pratt, 1996; Villamil \& De Guerrero, 1996; McGroarty \& Zhu, 1997; De Guerrero \& Villamil, 2000; Di Giovanni \& Nagaswami, 2001; Zhu, 2001; Liu \& Sadler, 2003; Tuzi, 2004; Hewett, 2006; Jones et al., 2006; Guardado \& Shi, 2007; Ho \& Usaha, 2009; Anderson et al., 2010; Ho, 2010; Cho \& Cho, 2011; Ho \& Usaha, 2013; Lina \& Samuel, 2013; Vorobel \& Kim, 2014; Bradley, 2014; Pham \& Usaha, 2015). On the other hand, the remaining number of reviewed studies $(N=11)$ focused on EFL learners (Min, 2005; Liang, 2008, 2010; Liou \& Peng, 2009; Song \& Usaha, 2009; Cha \& Park, 2010; Chang, 2012; Hanjani \& Li, 2014; Razak \& Saeed, 2014; Ho, 2015; Saeed \& 
Ghazali, 2016). From this finding, it seems that whereas studies on peer review in the ESL context are dated back to the early decade, studies on peer review in the EFL context are dated to the last few years. This indicates that recently, EFL instructors and researchers have started giving attention to peer review in writing. Such studies in the EFL context have even extended peer review research in the ESL context and contributed to previous knowledge by adding further insights into the role of technological tools in facilitating learners' peer review since all of them integrated technological tools, including blogs, designed systems and social networks, such as Facebook into peer review.

Another interesting finding is that the learners engaged in ESL peer review contexts as documented in all above-mentioned previous studies except these studies (De Guerrero \& Villamil, 2000; Ho, 2010; Ho \& Usaha, 2009; 2013; Lina \& Samuel, 2013; Pham \& Usaha, 2015; Sullivan \& Pratt, 1996) are socio-culturally heterogeneous since they come from diverse socio-cultural backgrounds, such as Indians, Indonesians and Singaporeans. Moreover, some of these studies mixed ESL learners with native speakers of English in peer review practices (Anderson et al., 2010; Bradley, 2014; Cho \& Cho, 2011; Liu \& Sadler, 2003; McGroarty \& Zhu, 1997; Zhu, 1995, 2001). Unlike learners in the ESL peer review context, learners in the EFL peer review context belong to homogenous cultural backgrounds, including Taiwan, China, Iran, Arab and Korea. In other words, all these studies on EFL learners' peer review in writing focused on socio-culturally homogeneous groups of learners. The only exception is the two studies by Razak and Saeed (2014) and Saeed and Ghazali (2016) that although the learners are Arabs, they come from different Arab countries, including Yemen, Tunisia, Egypt, Sudan, Syria and Algeria.

Finally, in terms of the educational context, all the above studies in both ESL and EFL contexts have investigated peer review among university learners, mainly undergraduates, while only one study reported a mixture of undergraduates and postgraduates (Anderson et al., 2010). This indicates that more attention has been given to peer review in tertiary settings where students' levels of proficiency are high and time is available for peer review practices.

\section{Implications and conclusion}

The findings of the present review have several implications for ESL/EFL pedagogy in writing and future research on peer review, including CAPR. First, peer review is a socio-cognitive approach to writing that engages learners in reflection and interpretation of written texts as evidenced by their interactional comments in the task/learning space (Fig. 2). Although peer review situations are unique, the findings of the review have implications for all cases of investigating peer review in ESL/EFL contexts. More precisely, the findings provided further supportive evidence to previous research acknowledging how learners through interaction in the learning space in peer review activities verbalize what and how they think of the texts and assist one another to detect problems in their texts and solve them. Hence, this eventually will help them accomplish their tasks and enhance the quality of their written texts.

While the above implications underlie the learners' interactional feedback exchanges in the learning space, interaction exchanges in the social space should not be discouraged by instructors, especially in the CAPR. In other words, ESL/EFL learners should not be urged by their instructors to steer away from social interaction in peer review. This is because, as indicated by the findings of the present study, social interaction in 


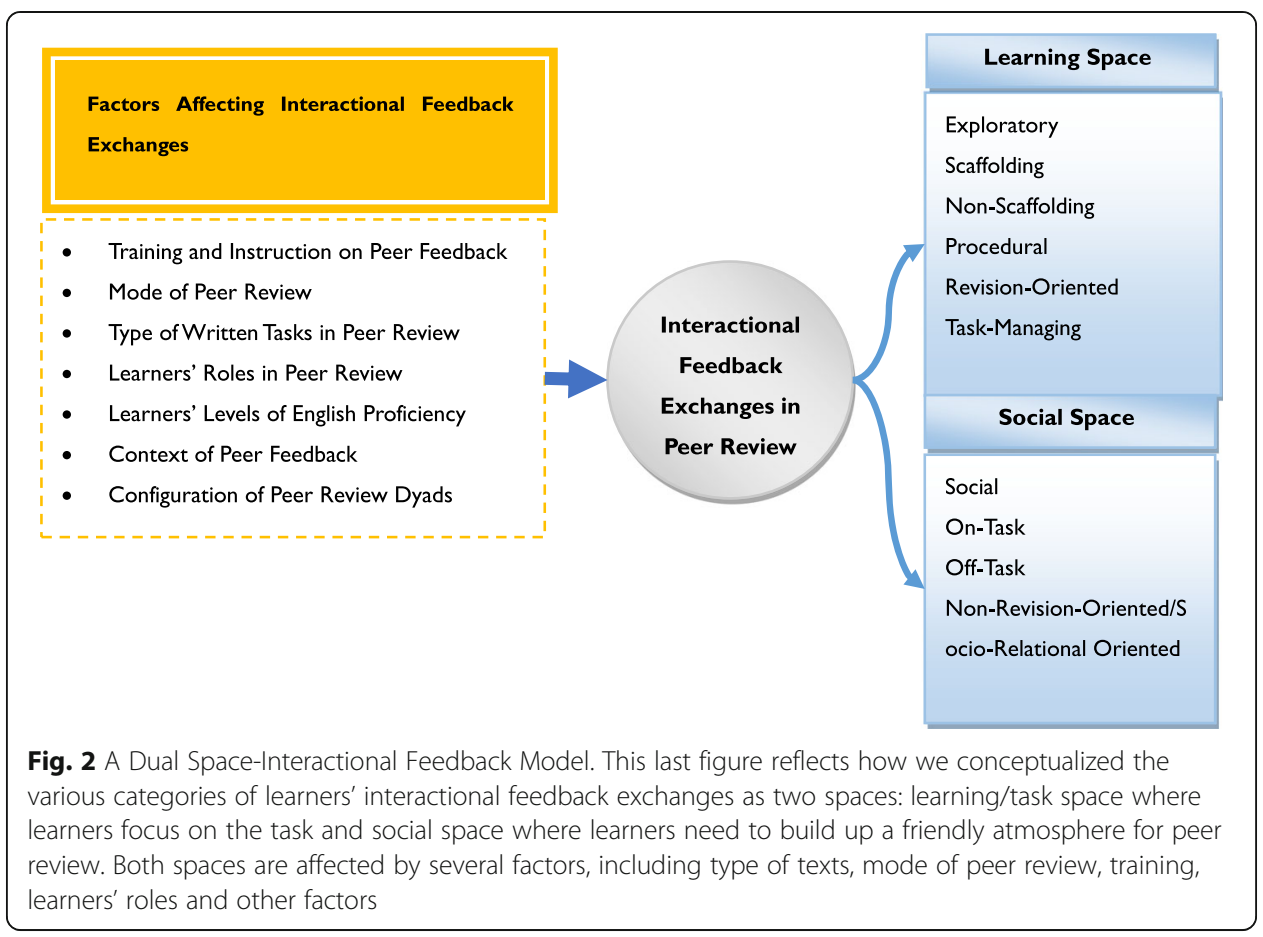

peer review is a means to establishing shared understanding, admission of misunderstanding or errors, a friendly atmosphere and mutual respect among learners. This, in turns, will motivate learners to accept one another's criticism and integrate their peers' suggestions into revising and improving their texts. Furthermore, social interaction in peer review provides learners with a space for using English as a means of communication and socialization. This implies that learners can find opportunities for using English for communicating on matters irrelevant to the task, especially in CAPR, which may be limited in the ESL/EFL classroom contexts.

As indicated by the findings of the review, approaching peer review from both spaces of interaction will provide researchers with an overall view of group review dynamics that do not disvalue one of these spaces at the expense of the other. This means that both spaces of interaction contribute to learners' pursuit of peer review. Although learners can establish these socio-relational aspects of learning through their interaction in the learning space especially when they are offered in a friendly manner, the non-task or off-task comments should be included in investigation of peer review. This is because off-task interaction tends to be more informal and casual. This will allow learners to get acquainted with one another and build social ties.

From the findings of the reviewed studies, few studies looked at how learners' interactional feedback facilitates their text revisions. It is evident that learners commonly integrate most of their peer feedback into revising their written texts with some variations as discussed above. Yet, there is still a need for future studies on how learners' interactional feedback exchanges facilitate their text revisions by using a textual analysis of learners' virtual interaction comments as to link them to subsequent text revisions.

To make learners' interactional feedback meaningful, this necessitates careful planning or preparation including training ESL/EFL learners through explicit 
instruction prior to peer review. The review of previous studies points at the role of training in fostering learners' interaction in peer review, especially globaloriented comments. Therefore, learners need to be trained by instructors on what and how to comment on their written texts through explicit instruction. Training assists learners to make their comments well-focused and revision-oriented comments that focus on both local and global issues of their texts.

Although previous research identified other important factors affecting learners' interactional feedback in peer review, further research should also examine the impact of learners' different roles in peer review and configuration of peer review dyads on their interactional feedback. The findings of most previous studies reviewed in this paper showed that ESL/EFL learners generated more globaloriented comments than local-oriented comments in peer review. Some of these studies on CAPR pointed to the delayed time in asynchronous peer review that enables learners to discuss more global issues of their texts than local ones. Specifically, the potential of the asynchronous mode of interaction in group work is due to the delayed time that allows learners to better reflect on their written texts at the global level. However, the delayed time in the asynchronous mode of peer review may not be valuable unless peer review discussions are scheduled at specific time. Scheduling peer review discussions at specific time implies that all learners are online present, and they ask and respond to one another within that specific time allocated for each discussion. This will engage them in discussing their texts more actively. Finally, future research should extend the use of peer review among school students in order to encourage them to review their writing through feedback and make them aware of the value of peer feedback in improving their writing.

\section{Additional file}

Additional file 1: The 37 reviewed studies. (DOCX $39 \mathrm{~kb}$ )

\section{Acknowledgements}

The authors acknowledge the assistance provided by other colleagues in the form of ideas and suggestions to accomplish the review.

Authors' contributions

All authors (MS, GK and MA) worked together, collaborated in collecting previous studies for the review, analyzing the data, writing up the review, editing it and completing the format according to the journal. They also read and approved the final draft to be submitted to the journal.

Competing interests

The authors declare that they have no competing interests.

\section{Publisher's Note}

Springer Nature remains neutral with regard to jurisdictional claims in published maps and institutional affiliations.

\section{Author details}

${ }^{1}$ Faculty of Languages and Linguistics, University of Malaya, Kuala Lumpur, Malaysia. ${ }^{2}$ Faculty of Medicine and Health Sciences, Universiti Putra Malaysia, Selangor, Malaysia. 
technical communication students in Sweden and in the United States. Journal of Business and Technical Communication, 24(3), 296-322.

Beason, L. (1993). Feedback and revision in writing across the curriculum classes. Research in the Teaching of English, $27(4), 395-422$

Bradley, L. (2014). Peer-reviewing in an intercultural wiki environment - Student interaction and reflections. Computers and Composition, 34, 80-95.

Cha, Y., \& Park, L. E. (2010). An analysis of synchronous interaction and its influence on EFL writers' revisions. Multimedia Assisted Language Learning, 13(2), 9-36.

Cho, Y. H., \& Cho, K. (2011). Peer reviewers learn from giving comments. Instructional Science, 39(5), 629-643.

Chang, C. F. (2012). Peer review via three modes in an EFL writing course. Computers and Composition, 29, 63-78.

Chang, L. (2010). Group processes and EFL learners, motivation: a study of group dynamics in EFL classrooms. TESOL Quarterly, 44(1):129-154.

Darhower, M. (2002). Interactional features of synchronous computer-mediated communication in the intermediate $L 2$ class: A sociocultural case study. CALICO Journal, 19(2), 249-277.

De Guerrero, M. C. M., \& Villamil, O. S. (2000). Activating the ZPD: Mutual scaffolding in L2 peer revision. The Modern Language Journal, 84, 51-68.

Di Giovanni, E., \& Nagaswami, G. (2001). Online peer review: An alternative to face-to-face? ELT Journal, 55(3), 263-272.

Fitze, M. (2006). Discourse and participation in ESL face-to-face and written electronic conferences. Language Learning \& Technology, 10(1), 67-86

Glaser, B. G. (1978). Theoretical sensitivity. Mill Valley: Sociology.

Glaser, B. G., \& Strauss, A. L. (1967). The discovery of grounded theory: Strategies for qualitative research. Hawthorne: Aldine de Gruyter.

Guardado, M., \& Shi, L. (2007). ESL students' experiences of online peer feedback. Computers and Composition, 24(4), 443-461.

Hanjani, A. M., \& Li, L. (2014). Exploring L2 writers' collaborative revision interactions and their writing performance. System, 44, 101-114.

Hayes, J. R., \& Flower, L. S. (1980). The dynamics of composing: Making plans and juggling constraints. In L. W. Gregg, \& E. R. Steinberg (Eds.), Cognitive processes in writing, (pp. 31-50). Hillsdale: Lawrence Erlbaum Associates.

Hedge, T. (2001). Teaching and learning in the language classroom, (vol. 106). Oxford: Oxford University Press.

Hewett, B. (2006). Synchronous online conference-based instruction: A study of whiteboard interactions and student writing. Computers and Composition, 23, 4-31.

Ho, M.C. (2015). The effects of face-to-face and computer-mediated peer review on EFL writers' comments and revisions. Australasian Journal of Educational Technology, 31(1), 1-15.

Ho, P. V. P. (2010). Blog-based peer response for 12 writing revision, PhD thesis 0. Nakhon Ratchasima: Suranaree University of Technology.

Ho, P. V. P., \& Usaha, S. (2009). Blog-based peer response for EFL writing: A case study in Viet Nam. AsiaCall Online Journal, 4(1), 1-29.

Ho, P. V. P., \& Usaha, S. (2013). The effectiveness of the blog-based peer response for L2 writing. Journal of Science Ho Chi Minh City Open University, 3(3), 27-44.

Hu, G., \& Lam, S. T. E. (2010). Issues of cultural appropriateness and pedagogical efficacy: Exploring peer review in a second language writing class. Instructional Science, 38(4), 371-394.

Hu, G. W. (2005). Using peer review with Chinese ESL student writers. Language Teaching Research, 9(3), 321-342.

Hyland, K., \& Hyland, F. (2006). Feedback in second language writing: Contexts and issues. Cambridge: Cambridge university press.

Jones, R. H., Garralda, A., Li, D. C. S., \& Lock, G. (2006). Interactional dynamics in on-line and face-to-face peer-tutoring sessions for second language writers. Journal of Second Language Writing, 15, 1-23.

Levi Altstaedter, L. (2016). Investigating the impact of peer feedback in foreign language writing. Innovation in Language Learning and Teaching, 1-15.

Liang, M. (2010). Using synchronous online peer response groups in EFL writing: Revision-related discourse. Language Learning \& Technology, 14(1), 45-64.

Liang, M. Y. (2008). SCMC interaction and EFL writing revision: Facilitative or futile? Proceedings of E-learn 2008, $2886-2892$.

Lin, S. S. P., \& Samuel, M. (2013). Scaffolding during peer response sessions. Procedia-Social and Behavioral Sciences, 90, 737-744.

Liou, H. C., \& Peng, Z. Y. (2009). Training effects on computer-mediated peer review. System, 37, 514-525.

Liu, J., \& Sadler, R. W. (2003). The effect and affect of peer review in electronic versus traditional modes on L2 writing. Journal of English for Academic Purposes, 2, 193-227.

Lockhart, C., \& Ng, P. (1995). Analyzing talk in ESL peer response groups: Stances, functions, and content. Language Learning, 45(4), 605-651.

Long, M. H. (1983). Native speaker/non-native speaker conversation and the negotiation of comprehensible input1. Applied linguistics, 4(2),126-141.

Long, M. H. (1985). A role for instruction in second language acquisition: Task-based language teaching. Modelling and assessing second language acquisition, 18, 77-99.

McGroarty, M. E., \& Zhu, W. (1997). Triangulation in classroom research: A study of peer revision. Language Learning, 47(1), 1-43.

Mendonca, C. O., \& Johnson, K. E. (1994). Peer review negotiations: Revision activities in ESL writing instruction. TESOL Quarterly, 28(4), 745-769.

Min, H. T. (2005). Training students to become successful peer reviewers. System, 33(2), 293-308.

Pham, V. P. H., \& Usaha, S. (2015). Blog-based peer response for L2 writing revision. Computer Assisted Language Learning, 1, 1-25.

Razak, N. A., \& Saeed, M. A. (2014). Collaborative writing revision process among learners of English as a foreign language $(E F L)$ in an online community of practice (COP). Australasian Journal of Educational Technology, 30(5), 580-599.

Saeed, M. A., \& Ghazali, K. (2016). Modeling peer revision among EFL learners in an online learning community. Electronic Journal of Foreign Language Teaching, 13(2), 275-292.

Song, W., \& Usaha, S. (2009). How EFL university students use electronic peer response into revisions. Suranaree Journal of Science and Technology, 16(3), 263-275.

Stanley, J. (1992). Coaching student writers to be effective peer evaluators Journal of. Second Language Writing, 1(3), $217-233$.

Sullivan, N., \& Pratt, E. (1996). A comparative study of two ESL writing environments: A computer-assisted classroom and a traditional oral classroom. System, 24(4), 491-501. 
Swain, M., \& Lapkin, S. (1998). Interaction and second language learning: Two adolescent French immersion students working together. The Modern Language Journal, 82, 320-337.

Swain, M., \& Lapkin, S. (2002). Talking it through: Two French immersion learners' response to reformulation. International Journal of Educational Research, 37, 285-304.

Swain, M. (2006). Languaging, agency and collaboration in advanced second language learning. In H. Byrnes (Ed.), Advanced language learning: The contributions of Halliday and Vygotsky (pp. 95-108). London, England: Continuum.

Tuzi, F. (2004). The impact of e-feedback on the revisions of $L 2$ writers in an academic writing course. Computers and Composition, 21(2), 217-235

Villamil, O. S., \& De Guerrero, M. C. (1996). Peer revision in the L2 classroom: Social-cognitive activities, mediating strategies, and aspects of social behaviour. Journal of Second Language Writing, 5(1), 51-75.

Vorobel, O., \& Kim, D. (2014). Focusing on content: Discourse in L2 peer review groups. TESOL Journal, 5(4), 698-720. Vygotsky, L. (1978). Mind in society. The development of higher psychological processes. Cambridge: Harvard University Press. Yang, Y. F. (2011). A reciprocal peer review system to support college students' writing. British Journal of Educational Technology, 42(4), 687-700

Zhu, W. (1995). Effects of training for peer response on students' comments and interaction. Written Communication, 12(4), 492-528,

Zhu, W. (2001). Interaction and feedback in mixed peer response groups. Journal of Second Language Writing, 10(4), $251-276$.

Submit your manuscript to a SpringerOpen ${ }^{\circ}$ journal and benefit from:

- Convenient online submission

- Rigorous peer review

Open access: articles freely available online

High visibility within the field

Retaining the copyright to your article

Submit your next manuscript at $\gg$ springeropen.com 